\title{
SOBRE A LIMITAÇÃO DO DIREITO DE LEGÍTIMA DEFESA MEDIANTE PONDERAÇÕES ENTRE BENS JURÍDICOS ${ }^{1}$
}

ON THE LIMITATION OF RIGHT TO SELF-DEFENSE BY PONDERING LEGAL GOODS

\author{
Volker Haas ${ }^{2}$ \\ Universidade de Heidelberg
}

\begin{abstract}
Resumo
O presente artigo objetiva investigar as limitações do direito de legítima defesa motivadas pelas ponderações entre bens jurídicos.

Palavras-chave

Legítima defesa. Ponderação jurídica. Bens jurídicos.
\end{abstract}

\section{Abstract}

This article aims to investigate the limitations of the right to self-defense motivated by the considerations between legal goods.

Keywords

Self-defense. Legal pondering. Legal goods.

\section{Introdução}

A visão tradicional ou corrente sobre a legítima defesa pode ser delineada da seguinte forma: o $\int 32$ do $\mathrm{StGB}^{3}$ não pressupõe fundamentalmente a ponderação entre bens jurídicos, diferentemente do

\footnotetext{
1 Tradução de Renato Kramer. Título em alemão: Zur Einschränkung des Notwehrrechts durch Güterabwägung, in: Kindhäuser, Urs/Pawlik, Michael (Hrgs.), Notwehr in Deutschland und China, 1. Aufl., 2020, S. 209-224.

2 Professor catedrático de Direito e Processo Penal de Universidade de Heidelberg, na Alemanha.

${ }^{3}$ StGB (Strafgesetzbuch) - Código Penal alemão.
} 
que estabelecem os regramentos do estado de necessidade dos $\iint 34$ do StGB, 228 e 904 do BGB. ${ }^{4}$ No entanto, o direito de legítima defesa deve, em casos excepcionais, ser restringido mediante as assim chamadas limitações ético-sociais do direito de legítima defesa, que não podem ser equiparadas, segundo o ponto de vista corrente, com a verificação geral de proporcionalidade. Como ponto de referência legal recorre-se ao elemento da imperatividade. Existindo os requisitos de uma limitação ético-social do direito de legítima defesa, então este é carecido de uma característica necessária para a justificação, que é ser imperativa. Como grupos de casos são discutidos especialmente em relação às consequências da defesa, agressões completamente desconsideráveis, agressões não intencionais e de pessoas com comportamento inculpáveis, agressões por ocasião de relações pessoais e agressões provocadas.

O presente artigo terá como foco apenas o primeiro grupo de casos. Trata-se, portanto, de casos, nos quais existe uma desproporção mais ou menos escancarada entre as lesões ameaçadoras através da agressão e as consequências eventuais da defesa para com o agressor. Como exemplo prototípico, a literatura cita frequentemente o caso do proprietário que atira contra o furtador, que subtrai para si suas cerejas. No entanto, não são apenas nomeadas agressões de bagatela em face da propriedade ${ }^{5}$, mas, também, agressões em face de outros direitos como agressões em face do direito de uso no trânsito através de bloqueios ilícitos de estacionamentos, ${ }^{6}$ em face do direito à própria imagem mediante fotografias não autorizadas, em face da honra através de injúrias ou em face do direito ao domicílio através da entrada de terrenos alheios. No segundo grupo de casos confronta-se, ao mesmo tempo, com o problema, se os casos envolvidos, em geral, de legítima defesa, classificam-se, ou se até mesmo devem ser ordenados, como casos de uma autorização de

${ }^{4}$ BGB (Bürgerliches Gesetzbuch) - Código Civil alemão.

${ }^{5}$ RGSt v. 23, p. 116 ss.; OLG Stuttgart DRiZ 1949, p. 42.

${ }^{6}$ Cf. BayOBLG NJW 1963, p. 824. 
estado de necessidade defensivo. O segundo grupo de casos é citado apenas rusticamente. Os últimos dois grupos de casos serão completamente ignorados.

O presente artigo é dividido da seguinte forma: primeiro, deve ser investigado como, historicamente, se chegou às concepções dogmáticas apresentadas de legítima defesa e se limitações da autorização de legítima defesa estão sedimentadas no regramento legal do \32 StGB. Em seguida, deve ser perguntado, se e se sim, de que forma limitações do direito de legítima defesa no sentido da ponderação entre bens jurídicos são declaráveis e/ou legitimáveis. Nesse sentido e por fim é colocado em discussão uma própria abordagem de fundamentação.

II. O desenvolvimento histórico das limitações do direito de legítima defesa

Recomenda-se iniciar, quando da constituição do desenvolvimento histórico, com o direito geral vigente da Prússia do ano de 1794, que, historicamente, situa-se na transição do absolutismo para o iluminismo. O direito geral vigente da Prússia do ano de 1794 exigia que o meio escolhido para a defesa do dano, que deve ser defendido mediante a legítima defesa, devesse estar em proporção. Permitia-se medidas de defesa mortais a favor da posse, apenas quando o dano ameaçado não pudesse ser substituído. Caso o agredido pudesse se esquivar sem perigo próprio, então um dano mortal ao agressor não deveria ser admitido (II 20 , \S 520 ss.).

A filosofia liberal iluminista virou-se, porém, a partir do fim do século XVIII de forma veemente contra a limitação das autorizações do direito de legítima defesa através da defesa da proporcionalidade entre bens jurídicos. Segundo ela, a autorização do direito de legítima defesa deriva dos seus respectivos titulares já no estado natural de direitos subjetivos concedidos, que são impostos de forma coativa com a sua ajuda. Na condição estatal passa-se a autorização para a imposição do 
direito de forma coativa por parte do cidadão ao Estado. A abdicação à autorização à autodefesa assegura o monopólio de violência estatal e, consequentemente, a paz jurídica. Porém, não estando o Estado, excepcionalmente, na situação de proteger os direitos de seus cidadãos, então renasce a própria autorização coativa do titular do direito ao direito subjetivo. Esta narrativa encontra-se em muitos estudiosos do Direito Natural daquele tempo. ${ }^{7}$ Nesse espaço, porém, não reproduziremos isso com detalhes, mas apenas a limitação da legítima defesa com as ponderações a ela inerentes. Nesse sentido já defendia C.C.E.Schmid em seu esquema de Direito Natural do ano 1793 - portanto, já antes da publicação da metafísica dos costumes do ano 1793 - o entendimento que ninguém poderia coagir o agredido, politicamente ou moralmente. ${ }^{8} \mathrm{Da}$ mesma forma, pertence a Kant a frase segundo a qual pertenceria ao âmbito da ética a "recomendação da moderação" na defesa. ${ }^{9}$ Qual forma de ponto-limite Kant tencionou, não se pode extrair do seu texto. Nesse sentido, deve ser levado em consideração o exemplo escolhido por Kant de uma agressão à vida, no sentido de que neste caso particular não haveria que se falar em limitação do direito de legítima defesa. ${ }^{10}$ Relembremos a lei geral vigente da Prússia de 1794, na qual poder-se-ia compreender explicitamente o caso regulado, no sentido de que o agredido seria capaz de esquivar-se à agressão através da fuga. O agredido, portanto, tem a possibilidade de fazer uma escolha em relação ao seu bem jurídico. A referência jurídica sobre possibilidade de fuga encontra-se, consequentemente, ligada, em um contexto direto, com o reconhecimento da necessidade de se realizar uma ponderação entre bens jurídicos. Além disso, deve ser levado em consideração que já naquela fase do requisito da necessidade nada foi colocado em dúvida.

${ }^{7}$ Detalhadamente Kühl, Freiheitliche Rechtsphilosophie, 2008, p. 323 ss.

${ }^{8}$ C.C.E.Schmid, Grundriß des Naturrechts, 1793, \168, p. 79.

${ }^{9}$ Kant, Metaphysik der Sitten, 2. ed., 1798, AA, p. 235.

${ }^{10}$ Assim Pawlik, Der rechtfertigende Notstand, 2002, p. 19. 


\section{DELICTAE, Vol. 6, No10, Jan..-Jun. $2021 \mid 11$}

O motivo pelo qual a moderação no exercício do direito de legítima defesa é confiada à moral, pode ser muito bem extraído com base no ponto de vista de Jakob, o qual compreendia isto como exigência de um dever de amor ao próximo, de tentar, mediante a utilização legítima da violência para a defesa, a utilização de meios benévolos. Apenas no homicídio para a repulsa de agressões à propriedade, fundamenta a ética, conforme a sua visão, um limite moral, o qual faz impossível o exercício do direito. ${ }^{11} \mathrm{O}$ imperativo de amor ao próximo - falaria hoje de um dever de solidariedade - não é abrangido, segundo o estudo Kantiano do direito, pelo conceito de direito. Ele é apenas um dever de virtude. ${ }^{12} \mathrm{O}$ direito se limita a um status negativo. É - observe-se apenas a relação entre os cidadãos - a personificação de relações jurídicas, que excluem os respectivos sujeitos de direito privado de qualquer interferência às esferas jurídicas alheias. ${ }^{13} \mathrm{~A}$ diferença reconhecível entre direito e moral torna-se visível também em Hoffbauer, o qual escreveu em seu livro sobre o Direito Natural de 1805 que a sujeição interna da pessoa poderia limitar o exercício de seu direito de defesa em muitos casos e que isto não diria respeito aos estudiosos do Direito Datural. ${ }^{14}$

Por fim, Fichte era também da opinião de que a não discriminada aqui é pensado a não móvel - propriedade estaria conectada com o direito de defender-se do agressor com perigo à vida. Todos têm o direito absoluto de não se encontrar em estado de violência, e mediante qualquer tipo de meio, evitar que isso aconteça. Ele compartilha as premissas que o direito não seria idêntico à moralidade. Deparando-se com a objeção de que seria dinheiro contra vida humana, então ele se esbarra com a réplica, no sentido de que ele não estaria falando de um caso de consciência. Para uma propriedade não móvel, não há para esse entendimento validade, isso

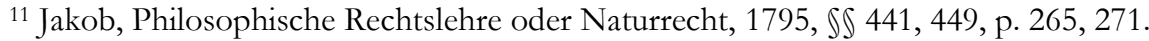

12 Kant (nota 5), p. 2448 ss.

${ }^{13}$ Cf. Pawlik, ZStW 114 (2002), 259, 277.

${ }^{14}$ Hoffbauer, Naturrecht, 3. ed., 1804, \ 235, p. 141.
} 
porque, o proprietário toma para si mais tarde a sua posse e poderia se colocar no estado anterior. ${ }^{15}$ Nesse sentido, Fichte segue ainda o modelo de regramento do direito vigente geral prussiano. Da mesma forma, queixou-se Welcker no dicionário do Estado de 1841 a mistura da moral com o direito. Poderia recomendar ao cidadão livre a limitação moral no exercício do direito de legítima defesa, caso, não sejam, em geral, o direito propriamente e a liberdade jurídica e segurança violados e destruídos. ${ }^{16}$

A ciência penal influenciada por Hegel do século 19 seguiu este rigoroso ponto de vista. Assim, alegou Berner, no sentido de que a medida da violência permitida não se dirigiria segundo o valor do direito a ser defendido, mas, sim, segundo as necessidades da defesa. ${ }^{17} \mathrm{~A}$ limitação do direito de legítima defesa foi rejeitada mediante a implementação da proporcionalidade entre bens jurídicos, de forma unânime. ${ }^{18}$

O novo paradigma de legítima defesa rigoroso influenciou também no seu tempo a legislação. Assim preconizava o $\int 41$ do Código Penal prussiano de 1851, no sentido de que o crime ou a contravenção não subsistiria, caso a ação fosse imposta pela legítima defesa. Legítima defesa seria aquela defesa, na qual seria necessário, defender uma agressão atual e ilícita contra si ou contra outrem. Em apoio notório ao Direito Penal prussiano, rejeitou-se, então, o Código Penal do império de 1871 no \53, sob aqueles requisitos, a existência de uma ação punível. Ambas codificações colocaram, apenas, sob a curatela da necessidade. A elementar da imperatividade não possuía nenhum significado próprio, como também

${ }^{15}$ Fichte, Rechtslehre, 1812, p. 112 ss.

${ }^{16}$ Roteck/Welcker, Staatslexikon, Bd. 11, 1841, p. 659.

${ }_{17}$ Berner, Lehrbuch des Deutschen Strafrechts, 18. ed., 1898, Neudruck 1986, p. 111; idem, Archiv des Criminalrechts, 1848, 547, 578 ss.

18 Levita, Recht der Notwehr, 1856, p. 202 ss.; Köstlin, Systema des deutschen Strafrechts, Allgemeiner Teil, 1855, Neudruck 1978, p. 81 ss.; Hälschner, Das preußische Strafrecht, 1. Teil, 1835, p. 258 ss.; idem, Das gemeine deutsche Strafrecht, 1. Bd., 1881, p. 475,484 ss. 
documenta claramente a literatura comentada. ${ }^{19}$ Os preceitos de legítima defesa podiam ter aduzido que um crime ou uma contravenção penal e/ou uma ação punível não seria existente se o agente tivesse agido em legítima defesa e tivesse respeitado quando da defesa os limites do necessário.

No entanto, a partir do último terço do século 19 aumentou o número dos críticos. Contexto ideológico foi a existência do positivismo etatístico. Modelo de contrato social da gênese jurídica exerceram em seu tempo nenhum papel importante. Assim criticou Geyer o homicídio moral da lei. ${ }^{20} \mathrm{Da}$ mesma forma criticava von Buri, que, segundo a lei, aquele que estivesse em situação de soltar um palavrão, de retirar da mesma um Pfennig $^{21}$, de arrombar uma janela ou de entrar em um terreno, podia ser morto caso o agredido não pudesse se ajudar de uma outra forma. ${ }^{22}$ Por isso é que no século 20 foram discutidas nas literaturas correspondentes propostas de limitação. ${ }^{23} \mathrm{O}$ projeto de lei proveniente de Radbruch datado do ano de 1922 apresenta o atestado destes esforços: na legítima defesa deve agir, consequentemente, apenas aquele que se defende ou um outro contra uma agressão atual e ilícita de forma adequada ( $\mathbb{2} 21$ Abs. 2 do projeto). Da fundamentação do projeto de 1925, que adotou o projeto do Código de 1922 sem nenhuma modificação, pressupõe que se tinha à vista o caso de um jovem que teria sido morto, porque teria subtraído um par de cerejas. Objetivo da versão do projeto era evitar resultados

${ }_{19}$ Beseler, Kommentar über das Strafgesetzbuch für die Preußischen Staaten, 1851, p. 185 ss.; Frank, Das Strafgesetzbuch für das Deutsche Reich, 18. ed, 1931, p. 159 ss.

${ }^{20}$ Geyer, in: Holtzendorff (Org.), Handbuch des deutschen Strafrechts, 4. Bd., 1877, p. 94; o mesmo. Grundriss zu den Vorlesungen über gemeines deutsches Strafrecht, 1. Hälfte, 1884, p. 81.

${ }^{21}$ Pfennig era a antiga unidade monetária na Alemanha.

22 von Buri, Der Gerichtssaal 30 (1878), 434, 464.

${ }^{23}$ Graf zu Dohna, in: FG für Rudolf Stammler, 1926, p. 253, 266. 
insatisfatórios sob o ponto de vista moral. ${ }^{24} \mathrm{~A}$ separação entre direito e moral foi mais uma vez, portanto, parcialmente revogado.

Após a segunda guerra mundial a comissão especial divergiu do projeto do Código Penal de 1962 acerca da elementar da imperatividade no preceito da legítima defesa, com o fim de poder evitar uma justificação por motivos ético-sociais. Especialmente pensou-se a comissão especial em agressões, que fossem insignificantes, de modo que a sua aceitação pudesse ser suportada. ${ }^{25} \mathrm{O}$ projeto de 1962 quis abdicar, conscientemente, da exigência de proporcionalidade dos bens jurídicos conflitantes entre si e sob o fundamento de que o direito não deveria ceder ante o injusto. Além disso, ele valeu-se contra a ponderação dos bens jurídicos afetados, de modo que, o ofendido, dificilmente, estaria em situação de realizar uma ponderação livre de emoções em virtude do perigo dos seus próprios bens jurídicos. Tendo em vista os casos de desproporção grosseira entre os bens jurídicos violados e aqueles atingidos mediante a defesa, então o projeto referiu-se à moralidade, a qual, segundo o Art. 2, Abs. $1 \mathrm{GG}^{26}$, limita de forma bem geral o exercício de direitos. O direito de legítima defesa conhece, assim, a limitação ético-social necessária, se o seu exercício for reprovado pela convicção jurídica da coletividade. ${ }^{27} \mathrm{O}$ projeto alternativo também consagrou as limitações ético-sociais da legítima defesa. No entanto, ele considerou uma regulamentação legal como impossível. A elementar da imperatividade não diz nada, se a legítima defesa for inadmissível e segundo quais princípios poderia chegarse a esta decisão. ${ }^{28}$

${ }^{24}$ Schubert/Regge, fontes sobre a reforma do direito penal e processual penal, 1. departamento, Bd. 1, 1995, p. 147, 203, 260.

${ }^{25}$ BT-DrS V/4095, p. 14.

${ }^{26}$ GG (Grundgesetz) - Constituição Federal alemã.

${ }^{27}$ Projeto de um Código Penal (StGB) 1962, p. 158.

${ }^{28}$ Projeto alternativo de um Código Penal, 2. ed., 1969, p. 51. 
De lege lata é controvertido, se o legislador quis limitar o direito de legítima defesa por motivos ético-sociais nos casos de desproporção crassa, mediante a elementar da imperatividade de modo adequado. A fração dos opositores diagnostica uma violação contra o art. 103 Abs. 2 GG. ${ }^{29}$ Esta discussão não deve continuar a ser realizada, pois ela não está relacionada efetivamente à problemática jurídico-material aqui interessada. Por isso, deve também bastar uma referência às controvérsias, se $\mathrm{o}$ art. 2 Abs. 2 EMRK proíbe o homicídio de um agressor para a defesa de bens materiais. ${ }^{30} \mathrm{~A}$ referência positivista sobre a lei não obsta da necessidade de dar uma fundamentação dogmática para a limitação das autorizações de legítima defesa.

III. Legitimação e fundamentação dogmática de ponderações entre bens jurídicos

Com isso pode dirigir-se a pequena investigação à segunda pergunta - nomeadamente ao problema, se e sob quais requisitos ponderações entre bens jurídicos são legitimáveis e/ou dogmaticamente justificáveis. Pode ser exigida, em geral, uma determinada proporcionalidade entre bens jurídicos? Esta pergunta deve, primeiramente, ser elucidada sob a base de uma abordagem liberal da legítima defesa. Cogitáveis são três possibilidades: em primeiro lugar, a limitação poderia já derivar dos princípios, os quais orientam a legítima defesa como o direito em si. Em segundo lugar, a limitação pode se alimentar de fontes normativas externas, as quais, por assim dizer, cercam o direito de legítima defesa de fora. E em terceiro lugar, seria possível

${ }^{29}$ Assim, por exemplo, Erb, in: Münchener Kommentar zum Strafgesetzbuch, Bd. 1, 3. ed., 2017, \32, nota 204; contrariamente, porém, Kindhäuser, in: Nomos Kommentar zum StGB, Bd., 1, 5. ed., 2017, \32, nota 99.

${ }^{30}$ A respeito NK-StGB/Kindhäuser, $\ 32$, nota 104 ss. 
observar a possibilidade de que pudesse ser abdicada, em resultado, toda e qualquer proporcionalidade entre bens jurídicos.

Em uma limitação interna do direito de legítima defesa, quem declara nos casos de uma desproporção crassa entre os bens jurídicos afetados o exercício do direito de legítima defesa como abuso do direito, então tem-se a consequência de que o defendente não pode mais se valer do seu direito. Esta visão baseia-se no projeto já mencionado de $1962^{31}$ e também no projeto alternativo. ${ }^{32}$ Além disso, ela é já defendida na literatura $^{33}$ e na jurisprudência. ${ }^{34}$ A proibição do abuso do direito deve marcar uma barreira imanente de todo direito subjetivo. No entanto, um abuso do direito pressupõe que o defendente exercesse sua autorização para uma finalidade juridicamente não reconhecida em lesar o agressor. Uma desproporção crassa entre os bens jurídicos afetados não deixa implícito, porém, absolutamente nada, no sentido de que o defendente persegue, ao invés da finalidade exigida de defesa, uma finalidade abusiva de lesão. ${ }^{35}$

Em parte, é defendida na literatura a posição no sentido de que a restrição juridicamente pretendida do direito de legítima defesa em casos de uma desproporcionalidade gritante resulta da utilização do princípio da proporcionalidade, o qual seria limitado não em face da relação entre Estado e cidadão, mas, sim, dominaria todo o ordenamento jurídico. $\mathrm{O}$ princípio da proporcionalidade deve ganhar validade em todos os direitos de intervenção e/ou em todas as formas de execução do direito. ${ }^{36} \mathrm{~A}$ este

${ }^{31}$ BT-DrS V/4095, p. 14.

32 Projeto alternativo de um código penal, 2. ed., 1969, p. 51.

33 Wessels/Beulke/Satzger, Strafrecht AT, 47. ed., 2017, \10, nota 512.

34 BGH NJW 1962, 308, 309; NStZ 2003, 424, 427; 2005, 85, 87; BayOBLG NJW 1963, 824; OLG Karlsruhe NJW 1986, 1358 s.

35 Cf. apenas von Rienen, Die "sozial-etischen" Einschränkungen des Notwehrrechts, 2009, p. 194 ss.

${ }^{36}$ Cf. apenas Schroeder, in: FS für Reinhart Maurach, 1972, p. 127, 139. 
ponto de vista é oposto, no sentido de que o princípio da proporcionalidade seria uma particularidade da relação de subordinação entre Estado e cidadão e, por isso, não seria transmissível sobre a relação de igualdade entre cidadãos. Este problema fundamental não pode ser resolvido neste espaço. Se se compara as autorizações de intervenções policiais, cujo exercício a favor do agredido a autorização de legítima defesa como subsidiário pode ser renunciado, se coloca igualmente a interessante pergunta, por que na execução jurídica estatal deve ser observado a defesa do perigo por ocasião da pertinência da ponderação de bens jurídicos - diferentemente do que na legítima defesa -, e não apenas possuir caráter de exceção. Esta questão não se refere apenas à dimensão quantitativa, em qual abrangência ultrapassam as ponderações de proporcionalidade, mas também, sobretudo, à dimensão qualitativa, de saber por que ponderações de proporcionalidade, em geral, devem desempenhar uma função. E esta pergunta não é respondida mediante a mera referência ao princípio da proporcionalidade. Neste contexto, deve ser observado que, possivelmente, os cenários de intervenção, que devem ser axiologicamente completamente diferentes em seu julgamento, cuja avaliação se orienta segundo diretrizes normativas diferentes, poderiam ser munidos com a mesma "etiqueta" "proporcional" ou "desproporcional". Caso este diagnóstico esteja correto, haveria pouco ganho na resolução da problemática de justificação recorrendo-se ao princípio da proporcionalidade.

A abordagem aparentemente majoritária na literatura parte do pressuposto de que uma limitação da autorização de defesa não pode ser extraída do pensamento da legítima defesa, que, ao contrário, carece de um princípio externo axiológico para poder esclarecer a omissão de consequências de defesa completamente desproporcionais do círculo de ações de legítima defesa legítimas. Nesse sentido, são seguidas as deduções das apologias da nova doutrina liberal de legítima defesa a partir do fim do século 18. Isso é válido de forma clara para a argumentação de Kant: este tinha derivado a autorização coativa justificada com o direito subjetivo 
pela contradição da seguinte frase: a coação que vai de encontro com uma ação, que é um obstáculo à liberdade, segundo as leis gerais e, consequentemente, é um injusto, está de acordo, segundo Kant, com a liberdade, segundo as leis gerais e, assim, é legítimo ${ }^{37}$. Pode-se também citar Berner, o qual se baseou no sentido de que a invulnerabilidade do direito seria existente igualmente em todo direito. ${ }^{38}$

Por isso, a limitação do direito de legítima defesa em casos de uma desproporção crassa é conduzida pela literatura, frequentemente, à ideia jurídica da solidariedade, ${ }^{39}$ cujo regime normativo o princípio de legítima defesa se sobrepõe. Segundo Pawlik trata-se da consideração, a qual um cidadão, como representante da coletividade deve a outro cidadão. $\mathrm{O}$ agressor conteria um tipo de prêmio para a sua suposta confiança ao direito no passado e, por assim dizer, um adiantamento a um comportamento esperado de confiança ao direito esperado por ele para o futuro. Em virtude disso, o agressor pertenceria, como de costume, à instituição da comunidade cidadã. ${ }^{40} \mathrm{O}$ conceito jurídico atual realiza o limite entre direito e moral, portanto, diferentemente do que aquele conceito jurídico demarcado por Kant. Porém, a dedução de Kant é plausível? A figura argumentativa da dupla negação ${ }^{41}$ desconhece que a legítima defesa não se esgota no momento de impedir a usurpação ilícita da esfera de liberdade por parte do agressor e/ou eliminar e reprimir o agressor do círculo jurídico próprio. Mediante o exercício da autorização de legítima defesa não são apenas retirados do agressor as vantagens de liberdade usurpadas, as quais, não concedem àquele como parte de sua liberdade de ação juridicamente protegida - como, por exemplo, no caso

${ }^{37}$ Kant (nota 5), p. 231 ss.

38 Berner, Archiv des Criminalrechts, 1848, 547, 561.

39 NK-StGB/Kindhäuser, \ 32 nota 101; MüKo-StGB/Erb, \32 nota 214; Jakobs, Strafrecht AT, 2. ed., 1983, 12/46; Frister, GA 1998, 291, 313.

${ }^{40}$ Pawlik, Das Unrecht des Bürgers, 2012, p. 245 ss.

${ }^{41}$ Pawlik, ZStW 114 (2009), 259, 269. 
imaginado de que o proprietário fecha o portão para evitar a entrada ilícita do agressor em sua propriedade. Ao contrário, o defendente tem, para alcançar este objetivo, de intervir no círculo jurídico do agressor, portanto, em cujas posições jurídicas. Apenas sob este requisito carece, em geral, de uma justificação mediante um preceito próprio.

Engländer através deste resultado concluiu que a conexão abstratamente necessária entre direito subjetivo e autorização coativa não subsistiria. ${ }^{42}$ Pois, não obstante esta análise correta, pode ser mantida a tese de que o direito subjetivo, pelo menos, tem que ser, conforme o motivo, necessariamente, realizável, para ser mais do que uma mera obrigação natural, pode também a abrangência jurídica da coação a ser utilizada, mediante o direito subjetivo afetado, não ser completamente determinada, mas, sim, só sob a consideração adicional da agressão na esfera jurídica do agressor. Assim, carece de uma fundamentação do porquê, excepcionalmente, cujo interesse são mais passíveis de proteção do que os do defendente. No caso de a intervenção, porém, não justificar mais mediante a legítima defesa, lesiona o defendente, também, no caso de uma defesa necessária, mas desproporcional, em razão de uma desproporção crassa entre os bens jurídicos, os direitos do agressor, de modo que deveria ser punido por delito de lesão. ${ }^{43}$ Os adeptos, que conduzem a limitação do direito de legítima defesa à ideia jurídica da solidariedade, poderiam, porém - como também esporadicamente é reconhecido consequentemente -, justificar a incidência de um delito de lesão ao agente. A ação poderia, ao contrário, ser comparada com aquela omissão de prestação de auxílio, conforme o $\int 323$ c StGB. ${ }^{44}$ Neste caso há necessidade ainda de uma discussão.

42 Engländer, Grund und Grenzen der Nothilfe, 2008, p. 84

${ }^{43}$ Cf. van Riemen, Die „sozialethischen“ Einschränkungen des Notwehrrechts, 2009, p. 209.

${ }^{44}$ Assim Pawlik (nota 34), p. 247. 
Além disso, alguns adeptos da doutrina da solidariedade se omitem em esclarecer, por que o defendente, em geral, tem que exercer junto ao agressor consideração solidária. Desta forma intervém o dever de tolerância nas situações de estado necessidade do $₫ 34$ StGB e o dever de prestação de omissão junto ao $\ 323$ c STGB apenas quando se o dever seja necessário para preservar os bens jurídicos do agredido frente a danos. Junto a uma agressão dolosa e culpável o próprio agressor pode se ajudar, na medida em que a agressão deixa de ocorrer ou se interrompe. Trata-se de casos, nos quais poderia ser falado de uma autocolocação em perigo espontânea por parte do agressor e, por esse motivo, poderia ser negada a sua necessidade de proteção. ${ }^{45}$ Porém, Frister baseou-se no sentido de que a não concessão de consideração solidária mediante escolha de um meio de defesa desproporcional provocaria, também, a perda de uma possibilidade por parte do agressor de que pudesse a lesão a seus bens jurídicos ser evitada mediante a cessação de sua ação. No âmbito da defesa de perigo agressiva, por ocasião da não concessão de ajuda solidária, permanece intacto a possibilidade do agredido se defender. ${ }^{46}$ Porém, pode depender apenas da situação no momento da decisão - como também nos termos do $\ 34 \mathrm{StGB}$ e $\int 323 \mathrm{c}$ StGB. Tendo o agressor tudo em suas mãos, então falta na necessidade uma consideração solidária.

IV. Constituição de uma abordagem própria para as limitações do direito de legítima defesa em casos de uma desproporção crassa

Porém, a necessidade de proteção do agressor poderia resultar no sentido de a imputação completa constituir sem qualquer minoração uma mera aproximação. Autonomia total é apenas uma construção ideal, que se retira de uma constatação empírica. Esta tese baseia-se em vários motivos: primeiro, teoricamente não é muito claro, sob quais requisitos pode ser

\footnotetext{
${ }^{45}$ Cf. Renzikowski, Notstand und Notwehr, p. 312 ss., o qual rejeita uma limitação.

${ }^{46}$ Frister, GA 1988, 291, 312 ss.
} 
atribuída uma vontade claramente livre. Segundo, são fatores que devem ser observados em certa medida em toda pessoa e que, segundo a opinião corrente diminui a imputação. E terceiro, é quase impossível, transmitir para a avaliação da autonomia fundamentos fáticos necessários de maneira completa. Isto é válido, especialmente, para o agredido, sob a perspectiva da situação de legítima defesa. Em suma, por isso que a limitação do direito de legítima defesa é legítimo em casos excepcionais - e isto independentemente, se o agredido defendia direitos alienáveis ou inalienáveis, como, por exemplo, a o direito à honra. À crítica de Hruschka de que, mediante as limitações ético-sociais do direito de legítima defesa ${ }^{47}$, empreenderia um passo a um sistema de sociedade totalitário, pode apenas com determinadas reservas ser admitida. $O$ resto mais ou menos irrevogável atribuído à heteronomia - portanto, a medida em natureza ou em responsabilidade alheia - é o motivo determinante, de o porquê o agressor também não ser expurgado da sociedade jurídica quando cometer uma agressão dolosa e culpável e não ser retirado o seu status como pessoa, como, em parte, porém, na literatura é aceito - dentre outros já em Feuerbach. ${ }^{48} \mathrm{O}$ agressor permanece pessoa de direito, como também alega Pawlik (se também com alguma outra fundamentação). ${ }^{49}$ Assim, poderia ter sido encontrado um possível ponto de abordagem, como se pode legitimar uma limitação ao direito de legítima defesa. Nesse sentido, não é errado - não obstante o valor limitado de esclarecimento - atribuir a este ponto de abordagem ao princípio da proporcionalidade.

Muito mais fácil deve ser fundamentar as limitações de legítima defesa - e, nesse sentido, devemos concordar com Hruschka -, se se defende um estudo de legítima defesa estatal. Sob um estudo de legítima

\footnotetext{
${ }^{47}$ Hruschka, Strafrecht nach logisch-analytischer Methode, 2. ed., 1988, p. 137 ss.

${ }^{48}$ Feuerbach, Lehrbuch des gemeinen in Deutschland gültigen peinlichen Rechts, 10. ed., 1828, \36; veja-se a respeito von der Pfordten, in: FS für Hans-Ludwig Schreiber, 2003, p. 359, 372.

49 Pawlik, ZStW 114 (2002), 259, 267.
} 
defesa estatal é aqui entendido um estudo, no qual é concedido ao agredido autorizações de defesa de forma primária no interesse público e proteção de seus interesses privados e apenas o status de um reflexo jurídico. Pode-se chegar a tal entendimento de legítima defesa, se se é da opinião de que o agressor age ilicitamente, pois infringe normas de comportamento, cuja observância ele deve em relação à sociedade jurídica. Uma tal compreensão normativa foi defendida no último terço do século 19, mediante a teoria imperativa. ${ }^{50}$ Ela influenciou até hoje a dogmática penal de maneira determinante. $O$ interesse público na defesa é fundamentado pelo fato de o agredido, mediante sua defesa, zelar pelo término da quebra do direito público e afirmar, desta forma, o direito. Uma limitação, tendo em vista o reconhecimento destas premissas, não seria feita a todo custo, porém, ela seria possível pelo fato de a própria sociedade jurídica estatal possuir a violência por definição sobre interesses e pelo fato de a implementação de interesses públicos ser limitada mediante o princípio da proporcionalidade.

${ }^{50}$ Thon, Rechtsnorm und subjectives Recht, 1978, p. 133. 